\title{
Nanojoining with Ni Nanoparticles for Turbine Applications
}

\author{
J. Awayes, I. Reinkensmeier, G. Wagner, and S. Hausner
}

Submitted: 18 November 2020 / Revised: 24 March 2021 / Accepted: 18 April 2021 / Published online: 26 May 2021

\begin{abstract}
Thermal joining can lead to high thermal stresses, undesired structural changes, and the associated loss of properties. In the turbine industry, monocrystalline materials are often used to take advantage of their high creep resistance and heat resistance. For process-related reasons, components are mechanically machined, and the contours usually have slightly work-hardened areas due to the mechanical processing. Downstream thermal processes at temperatures above $1100{ }^{\circ} \mathrm{C}$ can lead to recrystallization $(R x)$ at these areas, so that the properties are negatively affected. Usually, the joining temperatures for high-temperature brazing are in the range of $1200^{\circ} \mathrm{C}$, both in new installations and in the case of repairs. It is therefore desirable to reduce the joining temperature without changing the choice of filler material, which can lead to susceptibility to corrosion and oxidation. According to investigations of the last years, nanojoining with nanoparticles offers great potential. The joining temperature can be lowered due to the "surface effect." A considerable reduction in the size of the particles leads to a significant increase in surface atoms and thus in the specific surface area. The connection of the materials occurs predominantly due to sintering processes. After the joining process, the properties of a bulk material are available again. Mechanical properties comparable to those of brazing have already been achieved with silver nanoparticles (Hausner in WWA 56, 2015). Up to now, publications on the topic of nanojoining have largely referred to silver nanoparticles/ silver sintering. Due to the temperature application range, silver filler material cannot be used in gas turbines. Therefore, the first results of nickel nanoparticles for joining of the nickel-based superalloy PWA 1483 using induction heating are described in this paper. During joining, the parameters brazing temperature, holding time and the surface treatment of the base materials were varied. It becomes clear that the microstructure of the joint is dependent on temperature and holding time. Moreover, if the temperature is too low and holding time too short, only insufficiently sintering occurs, which leads to sample failure during the metallographic preparation. On the other hand, samples with a tensile shear strength of up to 165 MPa can be achieved with convenient joining conditions.
\end{abstract}

Keywords joining, nanomaterials, superalloys

\section{Introduction}

Nanojoining is a joining process that uses the surface effect of nanoparticles to achieve lower joining temperatures than the material characteristics describe. The nanoeffect is based on the ratio between the large surface and the volume, which represents an unstable state. This leads to sintering and melting processes even with less heat input compared to bulk material (Ref 1,2). By definition, brazing is a process in which the filler material becomes molten and wets the surfaces, which results in

This article is an invited paper selected from abstracts submitted to the 5th International Conference on Nanojoining and Microjoining (NMJ 2020) that was to be held from September 20 to 23, 2020, in Leipzig, Germany. The conference was postponed due to the coronavirus (COVID-19) pandemic. The paper has been expanded from the planned presentation.

J. Awayes and I. Reinkensmeier, Siemens Energy GmbH and Co. KG, Huttenstraße 12, 10553 Berlin, Germany; and G. Wagner and S. Hausner, Technische Universität Chemnitz, Erfenschlager Straße 73, 09125 Chemnitz, Germany. Contact e-mail: Ingo.reinkensmeier@siemens.com. a joint (Ref 3). When joining with nanoparticles, in particular sintering processes of the nanoparticles lead to bond formation, since nanoparticles in contact reduce their high surface energy through sintering processes before the melting temperature of the nanoparticles can be reached. Joining with nanoparticles is not a typical brazing process and is therefore termed "nanojoining."

For nanojoining, the material must be applied in the joining area, since flow processes do not occur sufficiently. The nanoparticles are processed and applied as a paste. After the joining process, the properties of the bulk material can be achieved and the re-melting temperature after the joining process corresponds to the melting point of the bulk material (Ref 1).

Up to the current state of the art, investigations about nanojoining mainly refer to joining with silver particles in the field of electronic packaging (Ref 4-7), whereby the properties achieved (e.g., reliability) are at least equivalent to those of conventional soldered joints. Recently, nanojoining has also been investigated for higher-stressed components (Ref 8-11). For applications in the high temperature range, higher demands are made on the temperature resistance, therefore nickel brazing materials are used (Ref 12). The challenge of nanojoining is to transfer the promising results of joining with silver nanoparticle to other materials, e.g., nickel, and to characterize them. This paper should contribute to this.

Components that react with counterproductive changes in properties at high heat input could be joined effectively with 
nanojoining. In the gas turbine sector, for example, components are manufactured monocrystalline (SX) or directional solidified (DS) in order to increase creep and mechanical resistance (Ref 12). Mechanical processing in the manufacturing route to create the final geometry leads to cold-formed areas. The heat influence during a brazing process, which is a standard joining process, stimulates recrystallization processes in these coldformed areas (Ref 13). The maximum temperature for brazing is around $1200{ }^{\circ} \mathrm{C}$ for nickel-based superalloys (Ref 14). However, recrystallization begins typically at approx. $1100{ }^{\circ} \mathrm{C}$. These lead to a fine-grained polycrystalline microstructure in the mentioned cold-worked areas. Therefore, the aim is to join at temperatures below $1100{ }^{\circ} \mathrm{C}$.

The precipitation temperature for nickel-based superalloys is approx. 800-900 ${ }^{\circ} \mathrm{C}$ (Ref 12). If the joining temperature would be around or below this temperature, it will be possible to change the process steps of the heat treatment or combine heat treatment and joining process. However, the reduction in temperature is also beneficial in terms of reducing energy consumption.

\section{Methodology}

For the joining tests, the nickel-based superalloy PWA 1483 was joined with Ni nanoparticles. PWA 1483 is a single crystal alloy, which has both, excellent hot corrosion resistance and castability. Thus, it is used in the hot gas path of gas turbines. Within these applications the joint must also withstand the high temperature (Ref 15).

The nanoparticles were first processed to a paste. The composition of the Ni nanopaste which was identified as an optimum regarding to the stability of the paste in previous works is shown in Table 1. For the preparation of the nanopaste, the solvent mixture of $\alpha$-Terpineol and $p$-Xylene was mixed with two alkylthiols, which have a stabilizing function and avoid agglomeration of the nanoparticles. Subsequently, spherical Ni nanoparticles with a particle size of 10 $100 \mathrm{~nm}$ (average particle size: $20 \mathrm{~nm}$ ) were added to the mixture. The dispersion of nanoparticles in the organic substances was performed using pulsed ultrasound. With this production route, a spreadable paste could be produced, which allows an application similar to conventional brazing pastes. Compared to commercially available Ag nanopastes, which exhibit metal contents of approx. $85 \mathrm{wt} . \%$, the $\mathrm{Ni}$ nanopaste produced in-house has a comparatively low metal content. An increase in the metal content as well as the investigation of other compositions of the Ni nanopaste is the subject of current work, whereby metal contents of up to 75 wt.\% (Ref 16) can be achieved in the meantime.

When joining with nanopastes, the application of pressure during the joining process is necessary to achieve a dense microstructure of the joints and to produce a stable joint (Ref 1 ,
17, 18). Therefore, a modified hydraulic press was used for the joining experiments, Fig. 1(a). The heating of the samples was carried out by means of induction. The desired pressure of 40 $\mathrm{MPa}$ was applied on the entire joining overlap surface of the sample with a punch, Fig. 1(a). The process is performed in air with comparative tests in argon inert gas. For tensile shear tests, three plates $\left(9 \times 40 \mathrm{~mm}^{2}\right)$ were joined together with an overlap of $7.5 \mathrm{~mm}$ (see Fig. 1b). For metallographic examinations, only two plates (same geometry) were joined.

For the joining experiments, the influence of joining temperature, holding time and surface treatment on the strength behavior (tensile shear strength) and the resulting microstructure of the joints were investigated, Table 2.

For all experiments, the heating rate was $150 \mathrm{~K} / \mathrm{min}$ and the samples were cooled down to room temperature freely in air. The joining temperature of $870{ }^{\circ} \mathrm{C}$ was selected because this would allow an integration of the joining process into the precipitation heat treatment of the nickel-based superalloy. The second joining temperature of $1020{ }^{\circ} \mathrm{C}$ was chosen to stay below $1100{ }^{\circ} \mathrm{C}$ to prevent recrystallization. In previous investigations, it was demonstrated that joining with Ni nanoparticles is possible in this temperature range (Ref 9). With 10 and 30 min, two different holding times were used, whereby the longer holding time allows stronger diffusion processes. With surface treatments, the samples were prepared for bonding. Fluoride ion cleaning (FIC) is performed for comparison with only ground surfaces. FIC is a typical treatment for repair, whereby the surfaces are "cleaned" from $\mathrm{Ti}$ and $\mathrm{Al}$ oxides at a temperature of $950{ }^{\circ} \mathrm{C}$ before brazing. Oxides in cracks or embedded oxides can also be removed because the process is performed with gas (Ref 19). FIC is only used for the joining temperature $1020{ }^{\circ} \mathrm{C}$. The application of the $\mathrm{Ni}$ nanopaste is carried out in a thickness of $20 \mu \mathrm{m}$ with a squeegee on the sample surface.

The investigation of all tensile shear samples at least 5 individual samples per varied parameter was performed with a universal tensile testing machine Zwick/Roell Z020 at room temperature and at a temperature of $750{ }^{\circ} \mathrm{C}$. For microstructure investigations, SEM and EDX analyses were performed with SEM NEON40EsB.

\section{Results and Conclusion}

\subsection{Influence of Process Parameters}

In following Fig. 2 a cross-sectional evaluation of joint in table form is given:

The parameter variation with a holding time of $10 \mathrm{~min}$ and a temperature of $870{ }^{\circ} \mathrm{C}$ achieved insufficient connection. The sample already fails during sample preparation. Both the increase of the temperature up to $1020{ }^{\circ} \mathrm{C}$ and the extension of the holding time up to $30 \mathrm{~min}$ result in evaluable samples.

Table 1 Composition of the in-house produced Ni nanopaste

\begin{tabular}{llr}
\hline Metal content, wt.\% & Ni (chemPUR, Karlsruhe, Germany) & 49.0 \\
Content of organic substances, wt.\% & $\alpha$-Terpineol (Carl Roth, Karlsruhe, Germany) & 24.5 \\
& p-Xylene (VWR, Darmstadt, Germany) & 24.5 \\
& 1-Tetradecanethiol $\left(\mathrm{CH}_{3}\left(\mathrm{CH}_{2}\right)_{13} \mathrm{SH}\right)$ (abcr, Karlsruhe, Germany) & 1.0 \\
& 1-Octadecanethiol $\left(\mathrm{CH}_{3}\left(\mathrm{CH}_{2}\right)_{17} \mathrm{SH}\right)$ (abcr, Karlsruhe, Germany) & 1.0
\end{tabular}



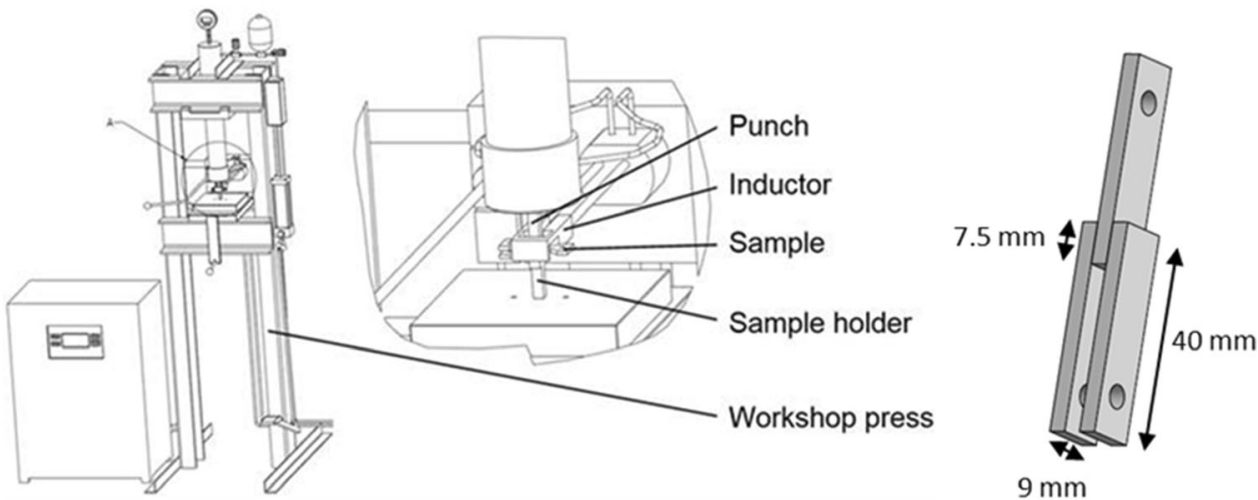

(a)

(b)

Fig. 1 (a) Schematic figure of the joining system and (b) sample geometry

Table 2 Used process parameters for the joining experiments

\begin{tabular}{llcllr}
\hline Temperature, ${ }^{\circ} \mathbf{C}$ & Holding time & Joining pressure, MPa & Surface treatment & Joining atmosphere & Thickness of paste application, $\boldsymbol{\mu m}$ \\
\hline 870 & $10 \mathrm{~min} / 30 \mathrm{~min}$ & 40 & Grinding & Air & 20 \\
1020 & $10 \mathrm{~min} / 30 \mathrm{~min}$ & 40 & Grinding & Air & 20 \\
1020 & $10 \mathrm{~min}$ & 40 & Grinding and FIC & Air & 20 \\
1020 & $10 \mathrm{~min}$ & 40 & Grinding & Argon & 20 \\
\hline
\end{tabular}

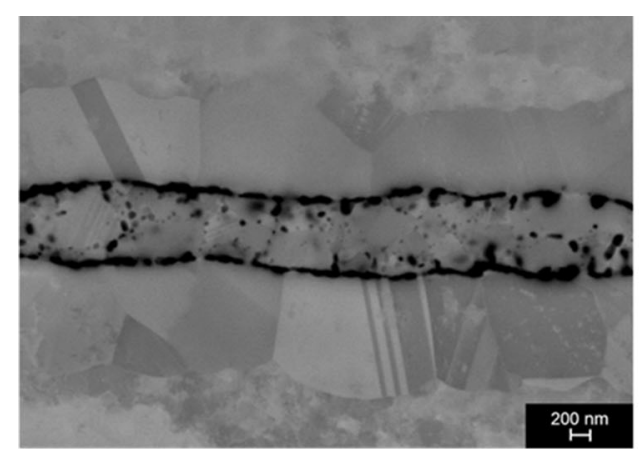

$1020^{\circ} \mathrm{C}-10 \mathrm{~min}$

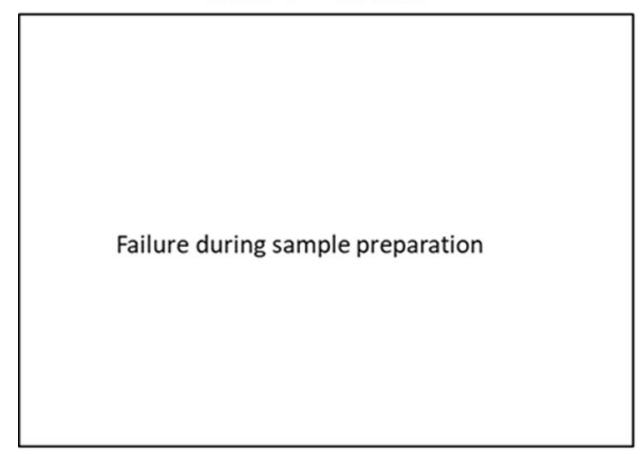

$870^{\circ} \mathrm{C}-10 \mathrm{~min}$

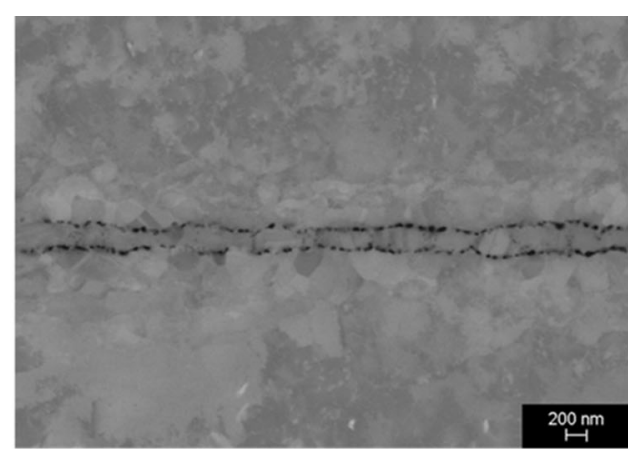

$1020^{\circ} \mathrm{C}-30 \mathrm{~min}$

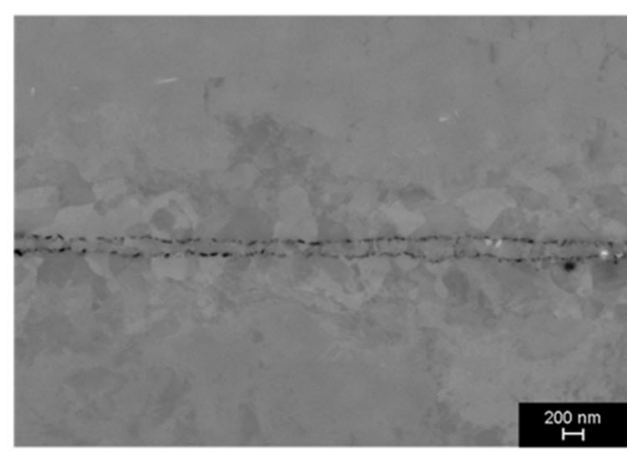

$870^{\circ} \mathrm{C}-30 \mathrm{~min}$

Fig. 2 PWA 1483 joined with Ni nanopaste; variation of joining temperature: 870 and $1020{ }^{\circ} \mathrm{C}$ and holding time: 10 and 30 min; joining pressure: $40 \mathrm{MPa}$, joined in air, ground surface; SEM mode: BSE

Along the interface between the joining seam and the base material, black areas are visible in all samples. Under the heading "Element analysis" it is shown that these are aluminum oxides. These oxides are formed in a linear arrangement. Despite the aluminum oxides, the particles bond to the base material as well as to each other. However, recrystallization still occurs in all samples. The reason for this is described in more detail under the heading "Recrystallization." The width of the joining seam and recrystallization zone varies 
depending on location in the joint (see next heading "Uniformity of Joint").

Since the samples show the comparable results among each other, the work is continued with the setting $1020{ }^{\circ} \mathrm{C} / 10 \mathrm{~min}$ to use the shortest process time.

\subsection{Uniformity of Joint}

Within the samples over the entire cross section, there are bigger differences in terms of microstructure than between the variation of temperature and holding times. In Fig. 3, images of a cross section of one sample are shown. These differences over the cross section occur equally for all joining cycles shown in Fig. 2.

In Fig. 3(a), the individually sintered particles, but still a spherical structure, can be seen. In these zones, the sintering process is not completed and therefore the joining seam is not yet fully compacted. Distributed between the particles, aluminum oxides are visible. The width of the joining seam is approx. $1.5 \mu \mathrm{m}$.

In Fig. 3(b), the particles have sintered together more strongly, and the joining seam is fully compacted. The particles are still individually recognizable, but their shape has changed from spherical to polygonal due to the compaction with the neighboring particles. The aluminum oxides have shifted to the interface as far as possible. Only small aluminum oxides are still present within the joining seam. The joining seam is narrowed to about $0.6 \mu \mathrm{m}$.
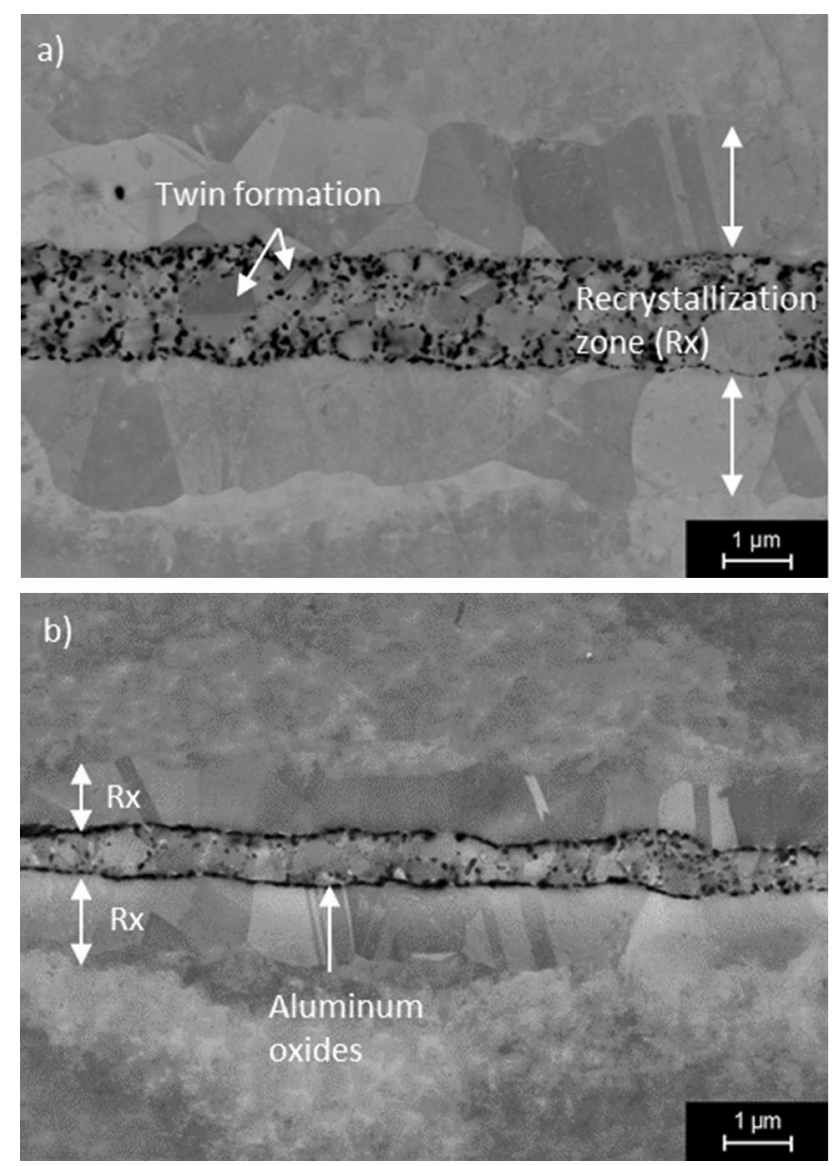

Fig. 3 PWA 1483 joined with Ni nanopaste (different areas in one sample); process parameters: $1020{ }^{\circ} \mathrm{C} / 10 \mathrm{~min} / 40 \mathrm{MPa}$, joined in air, ground surface; SEM mode: BSE
The extent of the recrystallization zone also differs within one sample and correlates with the microstructure just described. In Fig. 3(a), a larger recrystallization zone is visible. With an extension of approx. $1.5 \mu \mathrm{m}$ on each side, it is twice as large as in Fig. 3(b). In the following heading "Recrystallization" it is shown that one of the main reasons for the formation of the recrystallization is the applied joining pressure. Therefore, it is assumed that in case of incomplete sintering (Fig. 3a), the joining pressure is transmitted through the particles, so that the thicker recrystallization zone can be explained by this. This goes along with twinning within the particles and the recrystallization zone, see Fig. 3(a). In case of the compacted joining seam, the energy of the joining pressure is dissipated and therefore the recrystallization zone is thinner (Fig. 3b).

The incomplete sintered areas shown in Fig. 3(a) occur mainly in the edge areas of the samples. The areas in Figure 3(b) are in the center of the overlap zone. The inductor heats the material by eddy currents inside the samples. The areas in Fig. 3(a) may not have reached the desired temperature, because they are at the edge of the sample geometry. This could explain the difference in the microstructure within one sample.

\subsection{Recrystallization}

Although the joining temperature is below $1100^{\circ} \mathrm{C}$ (which is the typical temperature for the onset of recrystallization in PWA 1483), recrystallization processes have occurred, see Fig. 3. Possible causes are the EDM process, which was used to cut the sample from a block, the application of pressure during the joining process and the joining process itself.

With a heat application up to $1020{ }^{\circ} \mathrm{C}$ without joining process and thus also without pressure, the samples show no recrystallization in cross section (see Fig. 4). The assumption that the EDM process has an influence can therefore be excluded. The defective surface visible in Figure 4 is due to oxidation resp. scaling of the base material at the surface, which can also be seen macroscopically in all samples joined in air [see comparison of the samples before the joining process (Fig. 9a) and after the joining process (Fig. 9b and c)]. Normally, the surface of the joining area is protected from oxidation by covering it with the nanopaste. However, in the present case, joining was carried out without nanopaste, so that oxidation also occurred at the joining area.

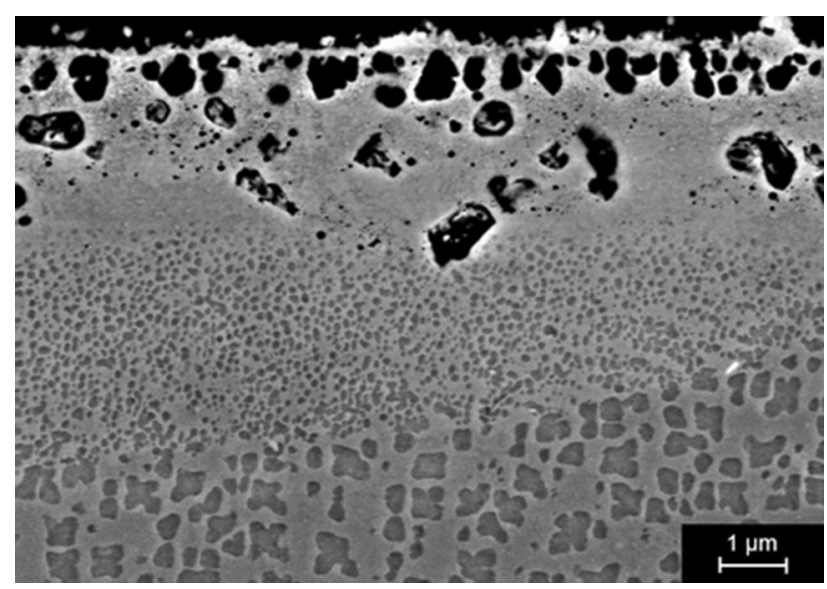

Fig. 4 Cross section of surface of PWA 1483 without nanopaste; etchant Kallings 2 process parameters: $1020{ }^{\circ} \mathrm{C} / 10 \mathrm{~min} / 0 \mathrm{MPa}$, heat treated in air, ground surface; SEM mode: BSE 


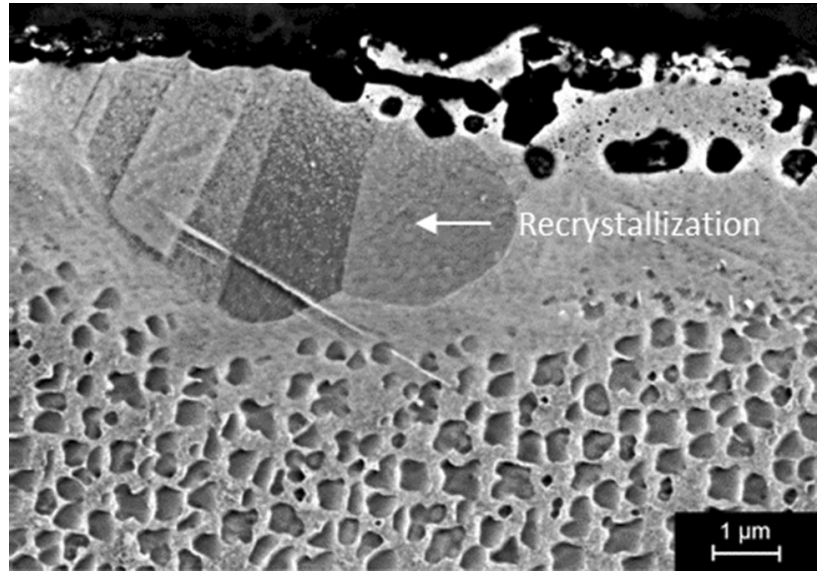

Fig. 5 Cross section of surface of PWA 1483 without nanopaste; etchant Kallings 2 process parameters: $1020{ }^{\circ} \mathrm{C} / 10 \mathrm{~min} / 40 \mathrm{MPa}$, heat treated in air, ground surface; SEM mode: BSE

The test was repeated with an additional application of pressure, but again without nanopaste, to eliminate the influence of diffusion. In Fig. 5 grains and twinning is visible. However, this are not as strong as in the samples with $\mathrm{Ni}$ nanopaste. Therefore, the combination of pressure application and the joining resp. diffusion processes seem to be the reason why recrystallization processes occur despite a joining temperature $<1100{ }^{\circ} \mathrm{C}$.

\subsection{Element Analysis}

A line scan was done along a line in this case $90^{\circ}$ offset to the joint. This provides qualitative information about the element distribution. On the left image (see Fig. 6) the joint is shown. The line scan is located within the white box. The white line in the right figure marks the exact travel path of the line scan. Each line must be considered separately, since the net intensity per element is represented. The height of the line has no meaning, only the amplitude, since every element distribution is detected along the white line. In the evaluation no quantitative analysis, but only the local variation of the element occurrence over the joint is shown.

The evaluation of molybdenum does not show any distribution differences. Titanium, tantalum, chromium and cobalt show a decrease in the joining seam including the recrystallization zone of approx. $2 \mu \mathrm{m}$. In the following, joining seam and recrystallization zone together are referred to as joining affected zone. Nickel has an increase in this area. The proportion of tungsten is only reduced in the joining seam. These distributions can be explained by the diffusion process from the base material to the joining seam.

In the case of aluminum, there is a clear increase in black spots. Aluminum has a high affinity to oxygen, and this is not excluded in the process (joining in air), so that an occurrence of aluminum oxide can be assumed. The evaluation of oxygen overlaps with the peak of chromium. In addition, the evaluation is overexcited at high excitation voltages. This results in no valid data, so that the evaluation of carbon and oxygen is omitted for line scan and mapping. However, with a point analysis, oxygen could be detected in the black areas, so it is quite safe to assume that the black areas are $\mathrm{Al}$ oxides. The distribution of the aluminum oxide can be evenly in the entire joining seam but can also cluster at the interfaces between

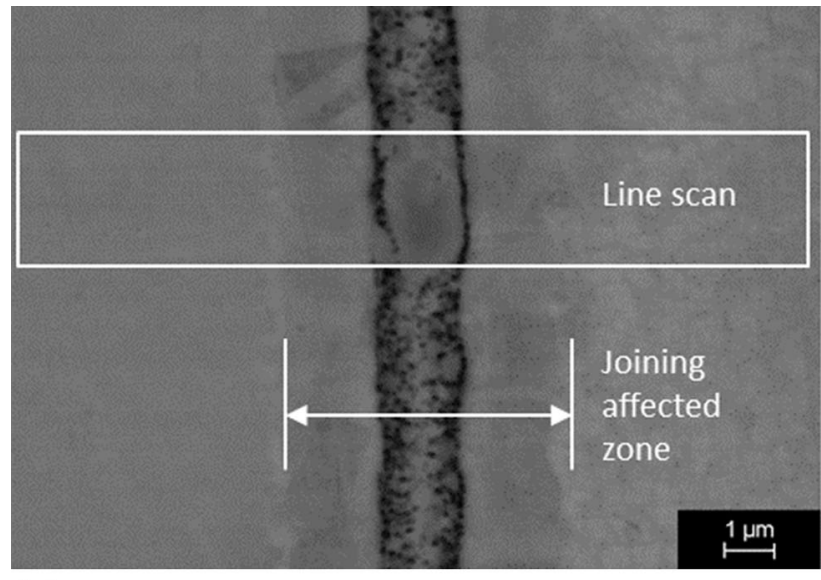

(a)

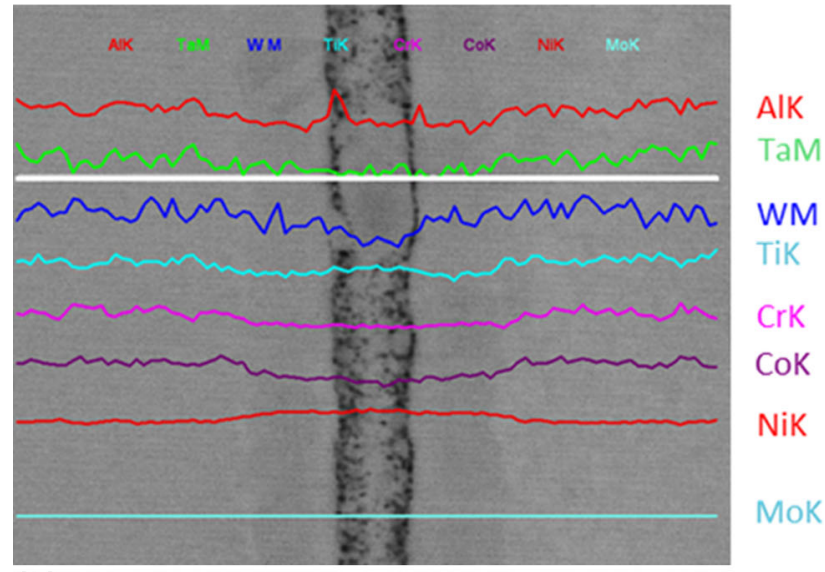

(b)

Fig. 6 Line scan of PWA 1483 joined with Ni nanopaste; process parameters: $1020{ }^{\circ} \mathrm{C} / 10 \mathrm{~min} / 40 \mathrm{MPa}$, joined in air, ground surface; SEM mode: BSE; $25 \mathrm{kV}$

joining seam and base material, resulting in two aluminum oxide bands as in Fig. 3(b) described as linear arrangement.

These results can also be reproduced on a local quantitative EDXS measurement with a minimum measurement field of 2 $\mu \mathrm{m}$. For aluminum, a mapping also shows the continuous accumulation in the black spots more clearly (see Table 3).

The table shows that the aluminum content in the joining seam is higher than in the recrystallization zone. Subsequently, it increases to the value that is present in the base material. This distribution is also visible in the mapping. The $\mathrm{Al}$ diffuses from the base material to the joining seam and combines with oxygen at the interface.

Especially the mechanical properties can be affected from the aluminum oxide because they are brittle and can act as a notch when force is applied along at which the sample fails. Especially the linear arrangement of $\mathrm{Al}$ oxides, as in Fig. 3(b), is critical.

\subsection{Modification of Surface Treatment: FIC}

To reduce the aluminum oxides, a test is carried out with a fluoride ion cleaning (FIC) of the PWA 1483 before the nanojoining process. Figure 7 shows that there is a different appearance of the joint compared to a merely ground surface. The joining affected zone is approx. $20 \mu \mathrm{m}$. The assignment of the recrystallization zone and the joining seam can hardly be 
Table 3 Left: EDXS-measurement with $2 \mu \mathrm{m}$ measurement field; right: Mapping of PWA 1483 joined with Ni nanopaste; process parameters: $1020^{\circ} \mathrm{C} / 10 \mathrm{~min} / 40 \mathrm{MPa}$, joined in air, ground surface; SEM mode: BSE

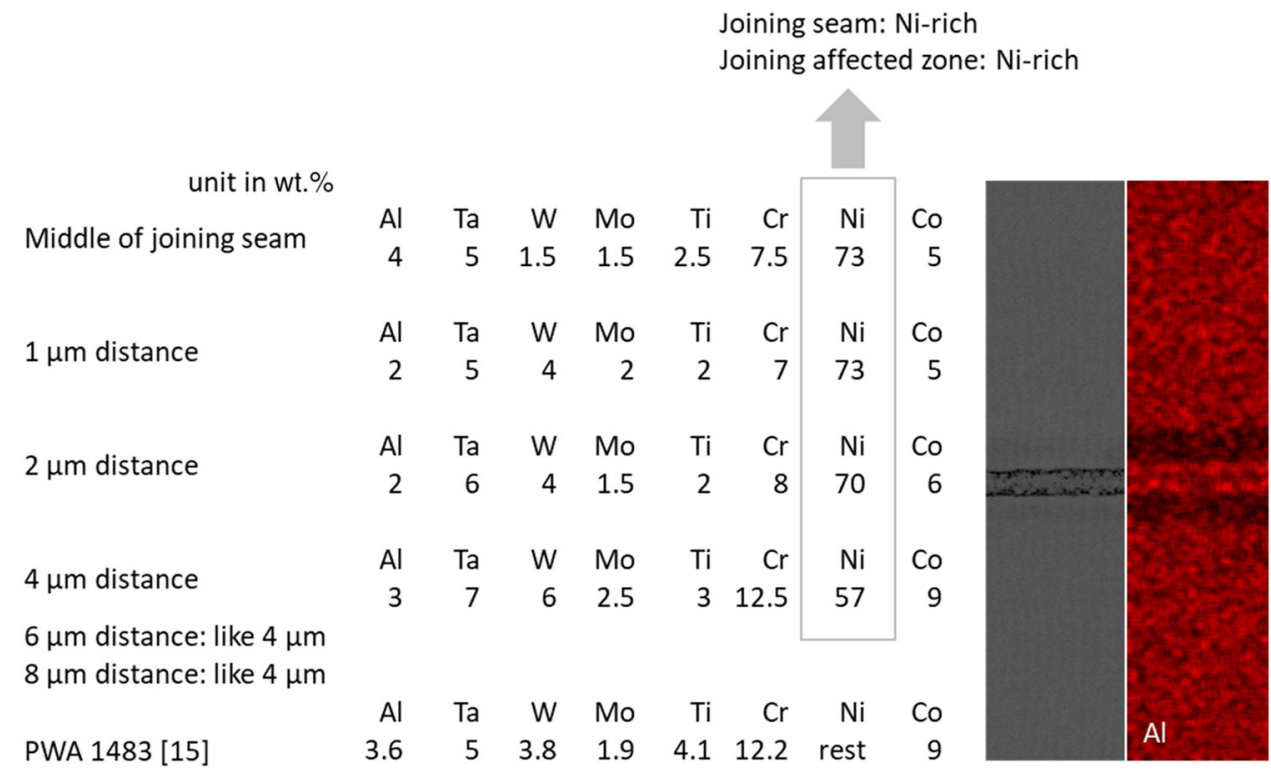

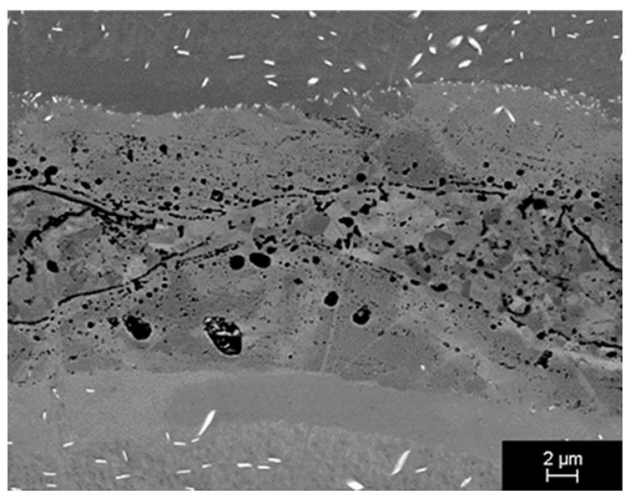

(a)

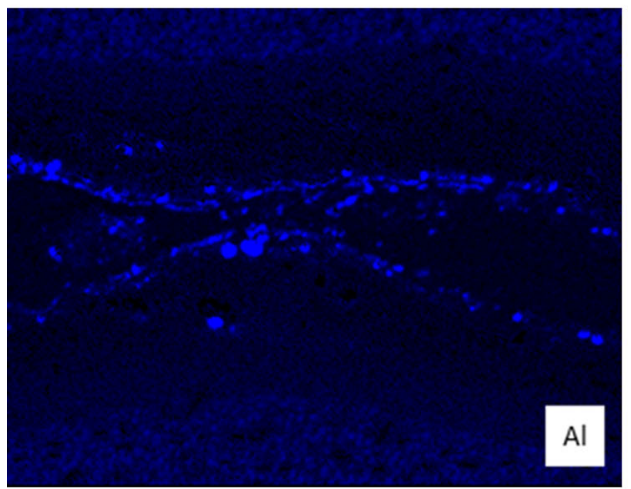

(b)

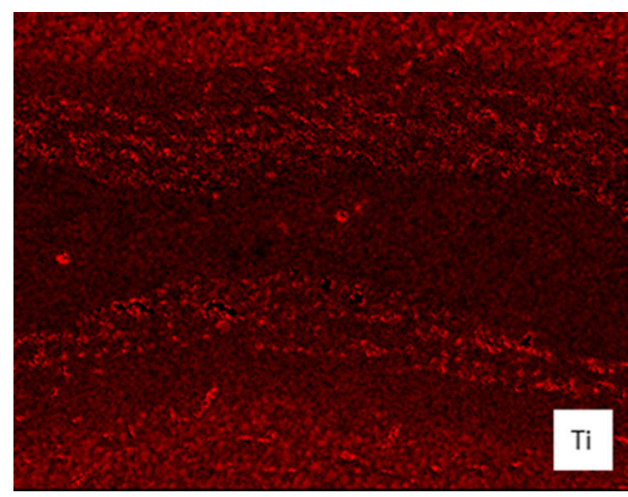

(c)

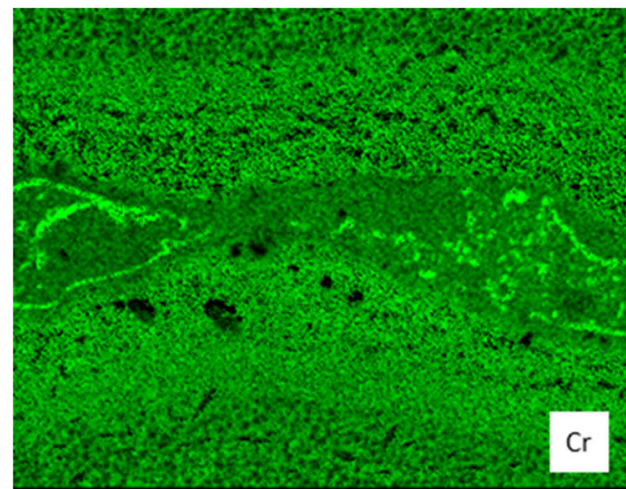

(d)

Fig. 7 EDX analysis of aluminum, titanium and chromium of PWA 1483 joined with Ni nanopaste; process parameters: $1020{ }^{\circ} \mathrm{C} / 10$ min/40 $\mathrm{MPa}$, joined in air, ground and Fluor Ion Cleaned surface; SEM mode: BSE, $10 \mathrm{kV}$

traced due to the wavy arrangement. However, the FIC did not completely avoid the formation of aluminum oxides, but the aluminum oxide layer at the interface between the joining seam and the base material is significantly thinner (see Fig. 7). Wavy zones of chromium oxides are also visible. Within the joining affected zone pores can be found. These have an extension of a few fractions of 1 micrometer up to 2 micrometers. Moreover, very small pores with a fine distribution are visible (see Fig. 7). 
Tensile shear strength of PWA 1483, joined with Ni nanopaste

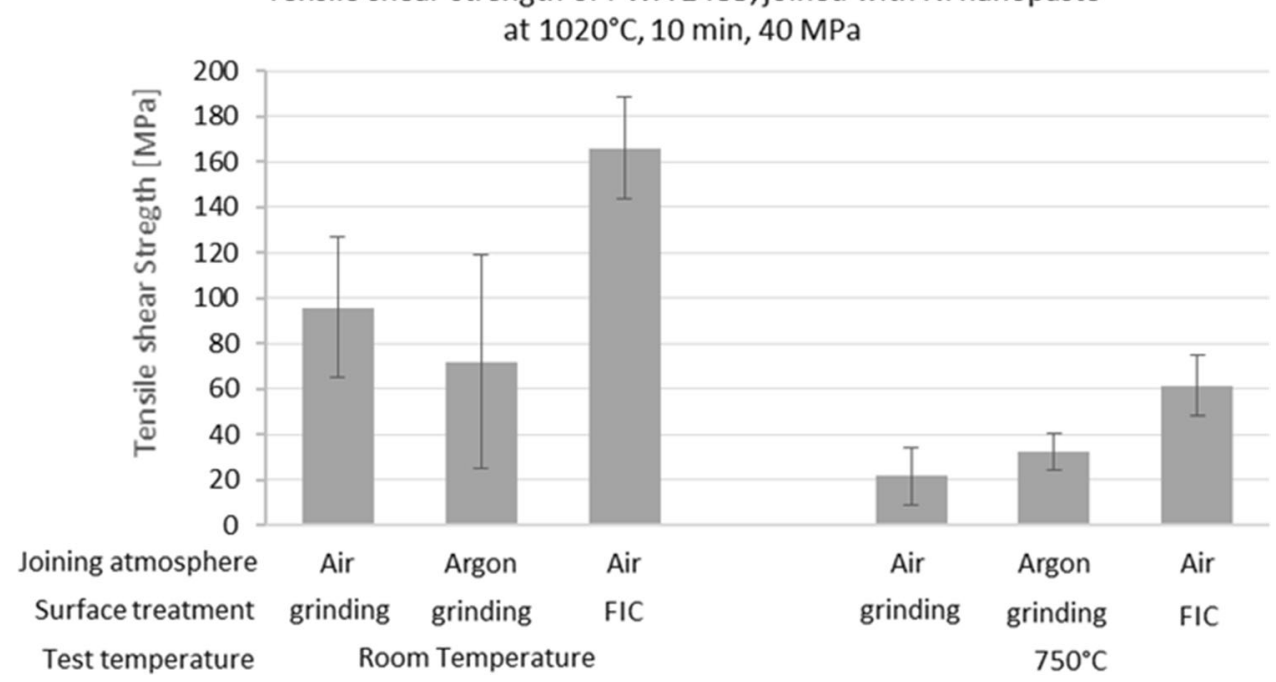

Fig. 8 Tensile shear strength of PWA 1483 joined with Ni nanopaste; process parameters: $1020{ }^{\circ} \mathrm{C} / 10 \mathrm{~min} / 40 \mathrm{MPa}$, joined in air or Argon, ground or Fluor Ion Cleaned surface; testing in room temperature and in $750{ }^{\circ} \mathrm{C}$ ambient temperature
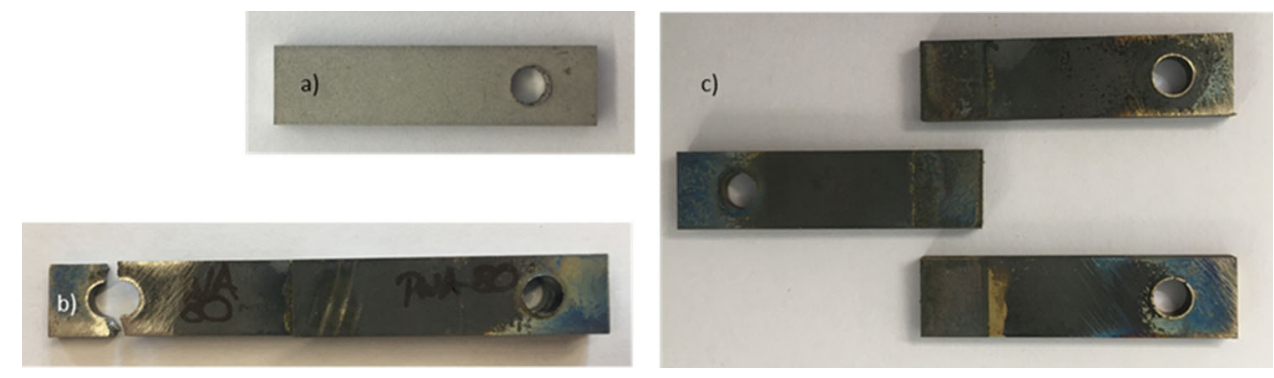

Fig. 9 Tensile shear test samples, Fluor Ion Cleaned; (a) before joining; (b) after joining at $1020{ }^{\circ} \mathrm{C} / 10 \mathrm{~min} / 40 \mathrm{MPa}$, tested at RT; (c) after joining at $1020{ }^{\circ} \mathrm{C} / 10 \mathrm{~min} / 40 \mathrm{MPa}$, tested at $750{ }^{\circ} \mathrm{C}$

These pores are typical for the FIC, since in addition to the aluminum oxides, other elements are also removed, such as aluminum (Ref 20). These pores are not filled in the process, since nanopastes show no flowability.

\subsection{Mechanical Testing}

The results of the tensile shear tests are shown in Fig. 8.

The samples were tested at room temperature (RT) and at an elevated temperature of $750{ }^{\circ} \mathrm{C}$. In addition to the presented samples with ground and FIC surface, which were joined in air, supplementary samples with ground surface were joined in argon atmosphere. Up to now, it is not clear, why when testing at RT, the in air joined samples exhibit higher strength values compared to those joined in argon and moreover, at test temperature of $750{ }^{\circ} \mathrm{C}$ it is vice versa. However, especially the samples tested in air show a high standard deviation, so that no clear conclusion can be reached regarding the strength values. The samples with the FIC surface each reach the highest values in both RT and $750{ }^{\circ} \mathrm{C}$. As shown above, aluminum oxides are still present in the joint of the FIC samples. However, these brittle and crack-prone oxides are thinner and not present in a linear arrangement as in the ground samples. Hence, it can be assumed that the linear arrangement, in addition to an increased occurrence of the aluminum oxides, has the biggest negative influence on the mechanical strengths. Anyway, the FIC samples in RT cracked in the base material (see Fig. 9), so that the "real strength" of the FIC samples is even higher than the determined $165 \mathrm{MPa}$.

The decrease in strength at elevated temperature can probably be attributed to the different coefficients of thermal expansion of nickel and aluminum oxide. This creates stresses that lead to fracture along the linear distribution. The FIC surfaces are also affected by this due to the presence of the aluminum oxides, but due to the thinner formation and wavy arrangement they also achieve higher mechanical shear strengths at $750{ }^{\circ} \mathrm{C}$.

\section{Conclusion}

The technology of nanojoining could initially be transferred to Ni nanoparticles and a nickel-based superalloy. Within the feasibility study, with the used joining parameters evaluable samples could be produced. The temperature could be decreased to $870{ }^{\circ} \mathrm{C}$ with a holding time of $30 \mathrm{~min}$. However, with a short holding time of $10 \mathrm{~min}$, the process shows more stable results with a higher joining temperature of $1020{ }^{\circ} \mathrm{C}$. Due to the higher temperature, an advanced diffusion can be achieved, which leads to better bonding between the particles as well as to the base material. Bigger differences in microstructural formation occur within one sample, compared 


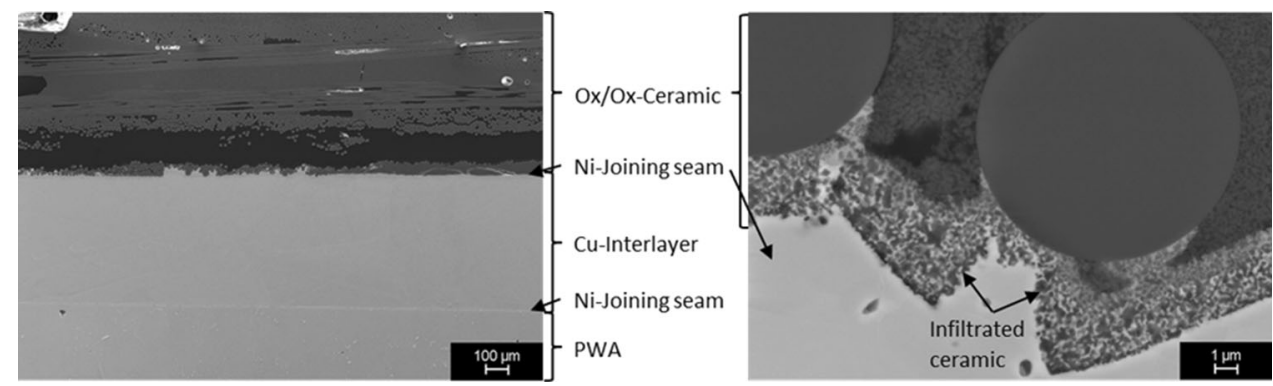

Fig. 10 PWA 1483 and $\mathrm{Al}_{2} \mathrm{O}_{3} / \mathrm{Al}_{2} \mathrm{O}_{3}$-ceramic, joined with Ni nanopaste and a Cu-interlayer; process parameters: $850{ }^{\circ} \mathrm{C} / 10 \mathrm{~min} / 40 \mathrm{MPa}, \mathrm{SEM}$ mode: BSE

to samples with different parameters. Besides dense and wellsintered areas, insufficiently sintered areas were also found at the edges of the samples, which is probably due to a lower temperature in the edge areas. However, the arrangement of the formed aluminum oxides is more critical. They are located along the joining seam on both sides at the interface between joining seam and base material. The process of fluoride ion cleaning can counteract this. The mechanical properties show significantly higher strength value due to the FIC. Samples without FIC have a high scattering, which indicates that the aluminum oxides are in a critical arrangement. It is also shown that recrystallization in the base material still occurs despite the reduction of joining temperature. According to the investigations, it is a combination of pressure and diffusion, which cause the recrystallization.

\section{Outlook}

For the high temperature application, a parameter study is pending, which describes the limits of the temperature reduction more precisely and the occurrence of recrystallization with pressure and diffusion influence. With regard to the application, joining under vacuum would be useful to create the manufacturing conditions for a gas turbine application, to observe the development of the critical aluminum oxides under exclusion of oxygen and to prove the mechanical values. In addition, other nickel-based superalloys are used in the gas turbine, for which the reduction of the joining temperature could bring a great added value. A transfer of the process to them would be of financial and technological advantage.

Experiments to apply the technology to a metal-ceramicjoint also show promising results (see Fig. 10). As metal-, the nickel-based superalloy PWA 1483 was used. As ceramic, a porous $\mathrm{Al}_{2} \mathrm{O}_{3}$-fiber-reinforced $\mathrm{Al}_{2} \mathrm{O}_{3}$-ceramic $(\mathrm{Ox} / \mathrm{Ox}$-Ceramic) was used, which has a great potential for gas turbine applications. To reduce the thermally induced residual stresses that typically occur in such metal-ceramic joints, a ductile $\mathrm{Cu}$ interlayer was inserted into the joint. Thus, the structure before the joining process was PWA $1483-\mathrm{Ni}$ nanopaste- $\mathrm{Cu}$ interlayer- $\mathrm{Ni}$ nanopaste- $\mathrm{Al}_{2} \mathrm{O}_{3} / \mathrm{Al}_{2} \mathrm{O}_{3}$-ceramic. During the joining process, diffusion processes generate a bond between the $\mathrm{Ni}$ joining seam and the $\mathrm{Cu}$ interlayer without melting of the $\mathrm{Cu}$ interlayer. Images of a cross section of this joint are shown in Fig. 10. The left side presents the layered structure. On the right side the interface between $\mathrm{Ni}$ and $\mathrm{Al}_{2} \mathrm{O}_{3} / \mathrm{Al}_{2} \mathrm{O}_{3}$-ceramic is shown in larger magnification. It is noteworthy that the ceramic can be wetted by the Ni nanopaste without a metallization of the ceramic or an active element in the filler metal. It is known from heterogeneous catalysis that $\mathrm{Ni}$ nanoparticles in pores of $\mathrm{Al}_{2} \mathrm{O}_{3}$ lead to the formation of $\mathrm{NiAl}_{2} \mathrm{O}_{4}$ (Ref 21). It can be assumed that such mixed oxides are also formed in the present case and that they have a positive effect on the bonding of the ceramic. The good bonding is also evident from the fact that the $\mathrm{Ni}$ nanopaste infiltrates the ceramic up to a depth of about 2 $\mu \mathrm{m}$. These very promising results show an enormous potential of nanojoining also for joining of metal-ceramic-joints without the need for metallization of ceramics or active brazing filler metals.

\section{References}

1. S.Hausner, Potential von Nanosuspensionen zum Fügen bei Niedrigen TEMPERATUREN. Werkstoffe und Werkstofftechnische Anwendungen, 2015, (56), https://nbn-resolving.org/urn:nbn:de:bsz:ch1-qucosa191211

2. P.R. Couchman and W.A. Jesser, Thermodynamic Theory of Size Dependence of Melting Temperature in Metals, Nature, 1977, 269, p 481-483

3. DVS Media Arbeitskreis V6.1 (Hrsg.): Hartlöten: Eine Einführung. Düsseldorf, 2018

4. K.S. Siow and Y.T. Lin, Identifying the Development State of Sintered Silver (Ag) as a Bonding Material in the Microelectronic Packaging Via a Patent Landscape Study, J. Electron. Packag. Trans. ASME, 2016, 138, p 020804. https://doi.org/10.1115/1.4033069

5. J. Yan, G. Zou, A. Wu, J. Ren, J. Yan, A. Hu and Y.N. Zhou, Pressureless Bonding Process Using Ag Nanoparticle Paste for flexIble Electronics Packaging, Scri. Mater, 2012, 66, p 582-585. https://doi. org/10.1016/j.scriptamat.2012.01.007

6. T. Wang, X. Chen, G.-Q. Lu and G.Y. Lei, Low-Temperature Sintering with Nano-Silver Paste in Die-Attached Interconnection, J. Elec-tron. Mater, 2007, 36, p 1333-1340. https://doi.org/10.1007/s11664-007$0230-5$

7. T. Watanabe, M. Takesue, T. Matsuda, T. Sano and A. Hirose, Thermal Stability and Characteristic Properties of Pressureless Sintered Ag Layers Formed with Ag Nanoparticles for Power Device Applications, J. Mater. Sci.: Mater. Electron., 2020, 31, p 17173-17182. https://doi. org/10.1007/s10854-020-04265-y

8. D. Bridges, R. $\mathrm{Xu}$ and A. Hu, Microstructure and Mechanical Properties of Ni Nanoparticle-Bonded Inconel 718, Mater. Des., 2019, 174, p 107784. https://doi.org/10.1016/j.matdes.2019.107784

9. S. Hausner, S. Weis and G. Wagner, Joining of Steels at Low Temperatures by Ni Nanoparticles, DVS-Berichte, 2016, 325, p 278284

10. S. Hausner, M.F.-X. Wagner and G. Wagner, Microstructural Investigations of Low Temperature Joining of Q\&P Steels Using Ag Nanoparticles in Combination with $\mathrm{Sn}$ and $\mathrm{SnAg}$ as Activating Material, Appl. Sci., 2019, 9, p 539. https://doi.org/10.3390/ap p9030539

11. A. Hu, D. Bridges, S. Zhang and Z. Feng, Nanobrazing for Turbine Blade and Vane Repair, Adv. Mater. Process, 2017, 175, p 25-29 
12. R. Bürgel, H.J. Maier and T. Niendorf, Handbuch HochtemperaturWerkstofftechnik, Vieweg Teubner, Heidelberg, 2011

13. D.C. Cox, B. Roebuck, C.M.F. Rae and R.C. Reed, Recrystallisation of Single Crystal Superalloy CMSX-4, Mater. Sci. Technol. Conf., 2003, 19, p 440-446. https://doi.org/10.1179/026708303225010731

14. Oerlikon metco (Hrsg.): BRO-0010.4: An Introduction to Brazing. Issue 4, Switzerland, https://www.oerlikon.com/ecomaXL/files/metco/ oerlikon_BRO-0010.4_Introduction_to_Brazing_EN.pdf\&download= 1 Accessed from 16.10.20-14:00

15. B. Collins, "Modified PWA 1483 Nickel-Based Superalloy for Industrial Gas Turbine Application", Maser Thesis, University of Florida, 2007

16. B. Sattler, S. Hausner, G. Wagner, Feasibility, Processing Properties and Thermal BEHAVIOR of Ni Nanopastes Produced by ULTRASOUND-Enhanced Dispersing, IOP Conference Series: Materials Science and Engineering, submitted December 11, 2020

17. Y. Liu, H. Zhang, L. Wang, X. Fan, G.Q. Zhang and F. Sun, Effect of Sintering Pressure on the Porosity and the Shear Strength of the Pressure-Assisted Silver Sintering Bonding, IEEE Trans. Device Mater Reliab., 2018, 18, p 240-246. https://doi.org/10.1109/TDMR.2018.28 19431
18. S. Hausner, S. Weis, B. Wielage and G. Wagner, Low Temperature Joining of Copper by $\mathrm{Ag}$ Nanopaste: Correlation of Mechanical Properties and Process Parameters, Weld. World, 2016, 60, p 12771286. https://doi.org/10.1007/s40194-016-0381-1

19. R. Kornfeld, Fluoride Ion Cleaning as a Prebraze Process, Heat Treat. Prog., 2006, 05(06), p 38-39

20. M.T. Kim, S.Y. Chang, O.Y. Oh, J.B. Won, Fluoride Ion Cleaning of Gas Turbine Components Using PTFE Grease. Surf. Coat. Technol., 2006, 200(24), p 6740-6748

21. K. Mette, S. Kühl, A. Tarasov, M.G. Willinger, J. Kröhnert, S. Wrabetz, A. Trunschke, M. Scherzer, F. Girgsdies, H. Düdder, K. Kähler, K.F. Ortega, M. Muhler, R. Schlögl, M. Behrens and T. Lunkenbein, HighTemperature Stable Ni Nanoparticles for the Dry Reforming of Methane, ACS Catal., 2016, 6, p 7238-7248. https://doi.org/10.1021/ acscatal.6b01683

Publisher's Note Springer Nature remains neutral with regard to jurisdictional claims in published maps and institutional affiliations. 